\title{
Toll-Like Receptors and Targeted Therapy in Diabetes Mellitus
}

\author{
Ali Bazi ${ }^{1,2^{*}}$ \\ ${ }^{1}$ Clinical Research Development Unit, Amir-Al-Momenin Hospital, Zabol University of Medical Sciences, Zabol, Iran \\ ${ }^{2}$ Pediatric Gastroenterology and Digestive Diseases Research Center, Zabol University of Medical Sciences, Zabol, Iran
}

*Correspondence to Ali Bazi,

Tel/Fax: +985432232166

Email: m.baziali@gmail.com

Received March 9, 2017 Accepted May 29, 2017 Published online June 30, 2017

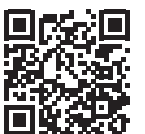

Please cite this article as follows: Bazi A. Toll-like receptors and targeted therapy in diabetes mellitus. Int J Basic Sci Med. 2017;2(2):7172. doi:10.15171/ ijbms.2017.13.

\begin{abstract}
Role of immune system in diabetes mellitus (DM) has been emerged for a long time. Since then, the majority of focus has been toward the role of adaptive immunity, while little thoughts credited a role for innate immunity in this process. By the emerging role of innate immunity in DM pathogenesis, especially toll-like receptors (TLRs) superfamily, it is expected that therapeutic approaches target these components in future of pharmaceutical research in diabetes. Keywords: Diabetes mellitus, Innate immunity, Toll-like receptor
\end{abstract}

Diabetes Mellitus and Immune System Diabetes mellitus (DM) is characterized with low grade inflammatory status. The inflammation within islet cells is considered a major determinant in beta cell dysfunction. ${ }^{1}$ This inflammatory state contributes to the pathogenesis of DM. However, the extent of the contribution, the mediators, and the potential role of targeting anti-inflammatory therapies are not well understood. Toll-like receptors (TLRs) are major receptors expressed on a variety of immune cells. The role of TLRs in the pathogenesis of DM has started to be unveiled in recent years. Attenuation of TLR-2 expression in the inflammatory cells of diabetic patients has been noted in association with modulated inflammatory state in these patients. ${ }^{2}$ It has been hypothesized that the release of large entities of damage-associated molecular pattern (DAMP) in DM can result in the persistent activation of TLR2 signaling. ${ }^{3}$ TLRs-derived signaling pathways have been recognized among 11 major signaling routes activated in DM type $2 .{ }^{4}$ Immunotherapy of DM targeting innate immunity components is a new approach in treatment of the disease. ${ }^{5}$ Specially, therapies aimed at targeting TLR-4 signaling pathway rendered a potential intriguing candidate. ${ }^{6}$ There are accumulating evidence that TLRs signaling may participate in DM complications and progression. ${ }^{7-9}$ Linagliptin, an antiglycemic therapeutic agent, has been shown to exert its beneficial effects on blood cerebrovascular circulation partly through the inhibition of TLR- 2 activity. ${ }^{10}$ In addition, it has been noted that insulin exerts its effects in part by inhibition of TLR-4 derived signaling pathways. ${ }^{11}$ This is interesting that the same signaling route involving TLR-4, inhibited by insulinmediated actions, is involved in the development of insulin resistance. ${ }^{12}$ In line with this, downregulation of TLR-4 has been a part of protective measures in animal models of diabetes. Herbal extract of Urtica dentata containing coumarin was shown to exert diabetes protective role through the suppression of TLR-4 signaling pathways. ${ }^{13}$ Despite these substantial evidence on the role of TLRs family in DM pathogenesis, pharmaceutical studies targeting these pathways have not been appropriately credited. Regarding the sufficiency of immune therapies targeting adaptive and cell mediated immunity in the treatment and prevention of DM during past decades, it seems that therapies have been oriented towards innate immunity to take the place of adaptive counterparts in this area.

Ethical Approval

Not applicable.

Competing Interests

None.

\section{References}

1. Eguchi K, Nagai R. Islet inflammation in type 2 diabetes and physiology. J Clin Invest. 2017;127(1):14-23. doi:10.1172/

Copyright (C) 2017 The Author(s); Published by Zabol University of Medical Sciences. This is an open-access article distributed under the terms of the Creative Commons Attribution License (http://creativecommons.org/licenses/by/4.0), which permits unrestricted use, distribution, and reproduction in any medium, provided the original work is properly cited. 
JCI88877.

2. Durrer C, Francois M, Neudorf H, Little JP. Acute highintensity interval exercise reduces human monocyte Tolllike receptor 2 expression in type 2 diabetes. Am J Physiol Regul Integr Comp Physiol. 2017;312(4):R529-R538. doi: 10.1152/ajpregu.00348.2016.

3. Sepehri Z, Kiani Z, Nasiri AA, Kohan F. Toll-like receptor 2 and type 2 diabetes. Cell Mol Biol Lett. 2016;21(1):2. doi:10.1186/s11658-016-0002-4.

4. Muhammad SA, Raza W, Nguyen T, Bai B, Wu X, Chen J. Cellular signaling pathways in insulin resistance-Systems biology analyses of microarray dataset reveals new drug target gene signatures of type 2 diabetes mellitus. Front Physiol. 2017;8:13. doi:10.3389/fphys.2017.00013.

5. Itoh A, Ridgway WM. Targeting innate immunity to downmodulate adaptive immunity and reverse type 1 diabetes. Immunotargets Ther. 2017;6:31-38. doi:10.2147/ ITT.S117264.

6. Burrows MP, Volchkov P, Kobayashi KS, Chervonsky AV. Microbiota regulates type 1 diabetes through Toll-like receptors. Proc Natl Acad Sci U S A. 2015;112(32):99739977. doi:10.1073/pnas.1508740112.

7. Szasz T, Wenceslau CF, Burgess B, Nunes KP, Webb RC. Toll-like receptor 4 activation contributes to diabetic bladder dysfunction in a murine model of type 1 diabetes. Diabetes. 2016;65(12):3754-3764. doi:10.2337/db16-0480.

8. Singh K, Agrawal NK, Gupta SK, Mohan G, Chaturvedi
S, Singh K. Increased expression of endosomal members of toll-like receptor family abrogates wound healing in patients with type 2 diabetes mellitus. Int Wound J. 2016;13(5):927-935. doi:10.1111/iwj.12411.

9. Buraczynska M, Zukowski P, Ksiazek K, Wacinski P, Dragan M. The effect of Toll-like receptor 4 gene polymorphism on vascular complications in type 2 diabetes patients. Diabetes Res Clin Pract. 2016;116:7-13. doi:10.1016/j. diabres.2016.04.002.

10. Hardigan T, Abdul Y, Ergul A. Linagliptin reduces effects of ET-1 and TLR2-mediated cerebrovascular hyperreactivity in diabetes. Life Sci. 2016;159:90-96. doi:10.1016/j. lfs.2016.02.067.

11. Zhang Z, Amorosa LF, Coyle SM, et al. Insulin-dependent regulation of mTORC2-Akt-FoxO suppresses TLR4 signaling in human leukocytes: relevance to type 2 diabetes. Diabetes. 2016;65(8):2224-2234. doi:10.2337/db16-0027.

12. Feng H, Su R, Song Y, et al. Positive correlation between enhanced expression of TLR4/MyD88/NF- $\kappa B$ with insulin resistance in placentae of gestational diabetes mellitus. PLoS One. 2016;11(6):e0157185. doi:10.1371/journal. pone.0157185

13. Wang J, Lu J, Lan Y, Zhou H, Li W, Xiang M. Total coumarins from Urtica dentata Hand prevent murine autoimmune diabetes via suppression of the TLR4-signaling pathways. J Ethnopharmacol. 2013;146(1):379-392. doi:10.1016/j. jep.2013.01.009. 